Openness/Intellect and Susceptibility to Pseudo-Profound Bullshit:

A Replication and Extension

\author{
Timothy F. Bainbridge ${ }^{1 *}$
}

\author{
Joshua A. Quinlan ${ }^{2}$ \\ Raymond A. Mar $^{2}$ \\ Luke D. Smillie ${ }^{1}$
}

${ }^{1}$ The University of Melbourne, Australia

${ }^{2}$ York University, Canada

* To whom all correspondence should be addressed: t.bainbridge@ student.unimelb.edu.au

This is the author manuscript accepted for publication and has undergone full peer review but has not been through the copyediting, typesetting, pagination and proofreading process, which may lead to differences between this version and the Version of Record. Please cite this article as doi: $10.1002 /$ per.2176

This article is protected by copyright. All rights reserved. 


\begin{abstract}
"Pseudo-profound bullshit" (PPBS) is a class of meaningless statements designed to appear profound. Profundity ratings for PPBS have been found to be negatively related to analytical thinking and positively related to epistemically-suspect beliefs (e.g., belief in the paranormal). Conceptually similar traits within the Openness/Intellect domain form a simplex, whereby traits are arranged along a single dimension from intelligence to apophenia (i.e., observing patterns or causal connections were none exist). Across two studies (total $N=$ 297), we attempted to replicate the O/I simplex and determine how it relates to perceiving PPBS as profound. Participants completed questionnaires measuring traits from the O/I simplex and provided profundity ratings for PPBS. Profundity ratings of PPBS tended to correlate negatively with intelligence and positively with apophenia. The association with intelligence generally reflected a greater ability to discriminate the profound from the pseudoprofound, whereas the association with apophenia reflected poorer discrimination in Study 1, with less conclusive results in Study 2. In both studies, the O/I simplex was closely replicated. The results suggest a link between the O/I domain and perceiving PPBS as profound, and tentatively support the theory that intelligence may protect against apophenia.
\end{abstract}

Key words: Openness/Intellect; Pseudo-Profound Bullshit; Simplex; Apophenia 
Openness/Intellect and Susceptibility to Pseudo-Profound Bullshit:

A Replication and Extension

Words are the instruments that politicians, priests, and poets use to inspire and influence us. These words are presented as meaningful, but to the cynical observer can sometimes appear partly or entirely vacuous. Consider a tweet from Deepak Chopra, a popular figure in alternative medicine, informing us that "Mind and matter are subtle and dense vibrations of consciousness" (Chopra, 2008-2016; as cited in Pennycook, Cheyne, Barr, Koehler, \& Fugelsang, 2015). This statement has the illusion of meaning but might be described as "utter bullshit" by the aforementioned cynic. Interestingly, there are substantial individual differences in the tendency to see meaning and profundity in these kinds of statements (Pennycook et al., 2015). The aims of the current research were two-fold: (1) to explore these individual differences in terms of their relevance to a useful framework within personality — the Openness/Intellect (O/I) simplex (DeYoung, Grazioplene, \& Peterson, 2012) — and (2) to determine whether these differences reflect the ability to discriminate between meaningful and meaningless content, or a propensity to see profundity in semantic content more generally.

\section{Pseudo-Profound Bullshit}

The first scholarly examination of "bullshit" was undertaken by Frankfurt (1986), who defined his subject as verbal statements designed to impress without any direct concern for truth (Frankfurt, 1986, 2005). The first empirical study of individual differences in bullshit receptivity was undertaken by Pennycook and colleagues (2015). These authors defined "Pseudo-Profound Bullshit" (PPBS) as any statement designed to inspire feelings of 
profundity without any direct concern for meaning or truth, with profundity defined as something "of deep meaning; of great and broadly inclusive significance" (Pennycook et al., 2015). Pennycook and colleagues identified sound syntactic structure as an important characteristic of PPBS, illustrating this point with two examples: "Hidden meaning transforms unparalleled abstract beauty" and, "Unparalleled transforms meaning hidden abstract" (Pennycook et al., 2015, p. 549). The first has a correct syntactic structure that gives it a façade of meaning, along with the presence of abstract, profound-sounding words (e.g., "transforms", "unparalleled"). In contrast, the second example contains the same profoundsounding words but lacks a correct syntactic structure, so is easily recognised as nonsense. ${ }^{1}$

Across four studies, Pennycook and colleagues (2015) asked participants to rate the profundity of PPBS statements. Ratings were made on a five-point Likert scale and were aggregated to form a "Bullshit Receptivity scale". Associations between these ratings and two broad classes of individual differences measures were then examined. The first class concerned one's capacity and inclination to engage in analytical thinking (e.g., measures of intellectual engagement and cognitive ability), whereas the second concerned epistemicallysuspect beliefs (i.e., beliefs that conflict with naturalistic conceptions of the world; Lobato, Mendoza, Sims, \& Chin, 2014). Pennycook and colleagues (2015) found that analytical thinkers perceived PPBS statements as less profound, whereas those endorsing epistemicallysuspect beliefs perceived PPBS statements as more profound. These findings have important

\footnotetext{
${ }^{1}$ Like Dalton (2016), some readers may wonder if PPBS is indeed meaningless. In response, Pennycook and colleagues (2016) noted that much of their PPBS (including the example above) was randomly generated by a computer algorithm with no concern with meaning, truth, or profundity, but rather with a concern only to have correct syntax and profound-sounding words. Although it is possible that any one of the statements was meaningful due to chance, it is highly unlikely that these statements, on the whole, captured anything beyond PPBS.
} 
implications for how we ascribe meaning and credibility to semantic information, as well as who may be more vulnerable to being misled by those who deal in bullshit. However, it would be helpful to elaborate on the nature of people's susceptibility to PPBS, and to understand these individual differences in the context of established frameworks within personality psychology.

\section{Why are some people misled by Pseudo-Profound Bullshit?}

The individual differences correlated with the endorsement of PBBS tell us who is more susceptible to PPBS (Pennycook et al., 2015), but can they tell us why? As these authors noted, a tendency to rate PPBS as profound may be explained by either a more liberal response bias (i.e., a lower threshold for rating any statement as profound) or by poorer discrimination (i.e., a lower ability to distinguish the profound from the meaningless). Because analytical thinkers tend to be more sceptical, Pennycook and colleagues (2015) expected that such individuals would be better at assessing the meaningfulness of each statement. They would thus "see through" PPBS statements and recognise genuinely meaningful and profound statements as such. Conversely, those affirming epistemicallysuspect beliefs were expected to be worse at assessing the merit of dubious claims and therefore struggle to distinguish PPBS from legitimately profound statements. To test this prediction, participants in the latter studies reported by Pennycook and colleagues (2015) were asked to rate the profundity of motivational quotes that arguably have some substantive depth and meaning (e.g. "A river cuts through a rock, not because of its power but its persistence”). A bullshit sensitivity measure was then calculated by subtracting profundity ratings for PBBS statements from those for the motivational quotes, which was then treated 
as an index of discriminatory ability. However, bullshit sensitivity was inconsistently associated with epistemically-suspect beliefs and analytical thinking. These equivocal findings, suggest that either discrimination is not the primary reason why analytical thinkers and those with epistemically-suspect beliefs respond differently to PBBS, or that discrimination was not adequately captured by this index.

One reason why the index may not have adequately captured the ability to distinguish PPBS from legitimately profound statements is the unbalanced nature of the Likert response scale used. This scale had many more options to indicate profound versus not profound evaluations (i.e., 1 [Not at all profound] compared to 2 [somewhat profound], 3 [fairly profound], 4 [definitely profound], and 5 [very profound]). This imbalance may have adversely affected the reliability of the bullshit sensitivity score. Specifically, participants who found PPBS statements to be on average at least somewhat profound (i.e. a rating of 2) would have sensitivity scores as high as 3 if they found the motivational quotations to be very profound (i.e., a rating of 5), despite such participants failing to realise that the PPBS statements were not at all profound. Conversely, participants who correctly realised that the PPBS was not at all profound (1) could have a bullshit sensitivity score of only 1 if they rated all the motivational quotations as only somewhat profound (2). The possibility of higher bullshit sensitivity scores for those who could not discriminate correctly compared to those who could may have led to the equivocal results for this index.

\section{Linking PPBS Susceptibility with Established Personality Frameworks}

The individual difference measures examined by Pennycook and colleagues (2015) seem, at first sight, like a diffuse assortment of traits, abilities, and beliefs from two distinct 
clusters (i.e., epistemically suspect beliefs and analytical thinking). However, epistemically suspect beliefs are closely connected to a range of clinical symptoms, including magical thinking, unusual perceptions, and eccentric behaviour, which have been described in terms of “positive schizotypy” (DeYoung et al., 2012; Vollema \& van den Bosch, 1995). Interestingly, there is an increasing body of evidence suggesting that both positive schizotypy and intelligence (which is closely related to analytical thinking; Sternberg, 1999) may fall within the O/I domain of the Big Five (Ackerman \& Heggestad, 1997; DeYoung, 2011; DeYoung, Carey, Krueger, \& Ross, 2016; DeYoung et al., 2012; Kwapil, Barrantes-Vidal, \& Silvia, 2008; Markon, Krueger, \& Watson, 2005). This suggests that the seemingly distinct clusters assessed by Pennycook and colleagues (2015) may in fact be closely connected. The O/I domain of the Big Five, or the Five Factor Model (Costa \& MacCrae, 1992; Goldberg, 1990), describes the shared variance between openness traits (e.g., aesthetics, imagination, and fantasy) and intellect traits (e.g., quickness, ingenuity, and ideas; DeYoung, Quilty, \& Peterson, 2007). At first, it is not clear how this domain might unite the apparently distinct concepts of positive schizotypy and intelligence. To explain this counterintuitive connection, DeYoung and colleagues (2012) devised a descriptive model of personality—the $\mathrm{O} / \mathrm{I}$ simplex — which demonstrates that these traits can be represented by a unidimensional arrangement of variables whose relative proximity describes their degree of relatedness, ranging from measures of cognitive ability and intelligence at the extremes of intellect to measures of apophenia at the extremes of openness (see Figure 1). DeYoung and colleagues (2012) replaced the term positive schizotypy with the term apophenia, which they defined as "the perception of patterns or causal connections where none exist" (DeYoung et al., 2012, p. 
$63)^{2}$, as they deemed that apophenia, unlike positive schizotypy, would be appropriate for non-clinical populations and might include mild, everyday experiences, such as "seeing faces in random visual patterns, mistaking random sounds for the calling of one's name... and believing that something may bring good or bad luck" (DeYoung et al., 2012, p. 66). Although the authors only included a single measure of intelligence within the simplex, it is implicit in their model that "intelligence" might capture a broader collection of closely related traits than those captured by traditional intelligence tests (e.g., working memory, analytical thinking styles). To avoid confusion, we reserve the word intelligence for the broad construct lying at the extreme end of the simplex and use cognitive ability to describe the specific construct assessed with standard intelligence tests.

\section{Figure 1}

If one compares the list of constructs in Figure 1 with those employed by Pennycook and colleagues (2015), the negative correlates of PPBS susceptibility are well-represented by constructs at the intelligence end of the simplex; especially intelligence and need for cognition - a close analogue of intellect (DeYoung, 2015). At the other end of the simplex, paranormal belief was positively correlated with PPBS susceptibility and was located at the apophenia end of the simplex, and many of the other positive correlates of PPBS are conceptually related to the constructs at the apophenia end of the simplex (e.g., conspiracist ideation and ontological confusions). Given these observations, the O/I simplex seems likely

\footnotetext{
${ }^{2}$ This definition of apophenia raises the concern of who decides which "patterns or causal connections" exist and which do not. After all, we cannot prove that a person who claims to see ghosts does not in fact see ghosts. Here, we use the phrase "where none exist" as an easy shorthand to indicate cases where the belief is generally believed to be unjustified given the information. For example, a creaking house does not indicate that ghosts exist, and someone who believed that it did would be experiencing apophenia (even if ghosts do in fact exist).
} 
to provide a useful organising framework for individual differences in PPBS susceptibility. Moreover, since PPBS presents participants with stimuli that elicit an experience of apophenia (i.e., the appearance of meaning where none exists), it provides a plausible candidate measure of apophenia.

\section{The Current Research}

In this paper, we present two studies intended to replicate and extend the work of Pennycook and colleagues (2015) in three distinct ways. First, we sought to replicate the pattern of correlations between individual differences constructs and PBBS susceptibility reported by Pennycook and colleagues (2015). Second, using Signal Detection Theory (SDT; Green \& Swets, 1966), we sought to determine whether PBBS susceptibility can be best explained in terms of differences in discrimination ability, differences in response bias, or a combination of the two. Finally, we sought to determine whether PBBS susceptibility can be incorporated into an existing structural model of personality, the $\mathrm{O} / \mathrm{I}$ simplex.

Because the equivocal results of Pennycook and colleagues' (2015) bullshit sensitivity score may reflect inadequate measurement of discriminatory ability, resulting from the unbalanced nature of their response scale, we improved upon this measurement in two major ways. First, we adopted a fully-balanced scale where participants rated whether they agreed or disagreed that the statement was profound (1 [Strongly disagree], 2 [Slightly disagree], 3 [Slightly agree], and 4 [Strongly agree]). Second, we formally distinguished between response bias (i.e., the tendency to rate all statements as profound) and discrimination (i.e., the ability to distinguish the legitimately profound from the pseudo-profound) using SDT. By applying SDT to judgements of PPBS profundity, we better assess whether the tendency to 
rate PPBS as profound reflects poorer discrimination of the profundity of PPBS statements relative to legitimately profound statements, or instead reflects a bias towards rating all statements as profound.

These aims were explored in two studies. Study 1 was largely exploratory, apart from a small number of pre-registered hypothesised correlations based on prior results (i.e., those replicating past results from Pennycook et al., 2015) (pre-registered at https://aspredicted.org/gepya.pdf). In contrast, Study 2 was a close replication of Study 1 with a few modifications based on issues encountered in Study 1 (pre-registered at https://aspredicted.org/up4rw.pdf).

\section{Study 1}

\section{Method}

Participants. One-hundred and forty-two University of Melbourne psychology students participated for course credit. Our target sample size was $N=133$, which provides $80 \%$ power to detect a typical correlation in personality psychology $(r=.24$; Fraley $\&$ Marks, 2007). All procedures received ethical approval at The University of Melbourne, and all participants provided informed consent. Two participants were removed from further analysis for failing to respond to three or more PPBS statements (25\% of statements). The remaining sample of 140 participants ( $67.1 \%$ female; $31.4 \%$ male; $1.4 \%$ other) included participants aged 18 to $46($ Median $=19 ;$ Interquartile range $=[18,20])$. Most participants self-identified as Caucasian/White (53.9\%) or Asian (37.9\%), and a majority (76.4\%) spoke English as a first language.

This article is protected by copyright. All rights reserved. 
Materials. All measures that employed a Likert scale (except profundity ratings, below) invited responses based on a scale with the points: 1 (Strongly disagree), 2 (Somewhat disagree), 3 (Neither agree nor disagree), 4 (Somewhat agree), and 5 (Strongly agree).

\section{Intelligence.}

The International Cognitive Ability Resource. Cognitive ability was assessed using the 16-item short form of the International Cognitive Ability Resource (ICAR; Condon \& Revelle, 2014). The ICAR is a relatively new, open-source measure of cognitive ability that shows promising reliability and validity (Condon \& Revelle, 2014). Cognitive ability was assessed as it putatively lies at the extreme end of the O/I simplex (DeYoung et al., 2012), and has been found to be negatively associated with PPBS ratings (Pennycook et al., 2015).

Cognitive Reflection Test. Cognitive Reflection concerns the tendency to question intuitively appealing response alternatives. It was assessed with the 7-item Cognitive Reflection Test (Toplak, West, \& Stanovich, 2014). Each question has an intuitively appealing, yet ultimately incorrect, answer, but is readily solvable if the initial answer is questioned (e.g., "A bat and a ball cost $\$ 1.10$ in total. The bat costs a dollar more than the ball. How much does the ball cost?"). Scores on a 3-item version of this test were previously found to be negatively associated with PPBS ratings (Pennycook et al., 2015) and we primarily included this measure to allow for comparison with this past finding. However, given its close relationship with intelligence (Toplak et al., 2014), we also anticipated Cognitive Reflection would be located toward the intelligence end of the O/I simplex.

\section{Openness and Intellect.}


Big Five. Openness and intellect were assessed with the Big Five Aspect Scales (BFAS; DeYoung et al., 2007) and the O/I facets of the 120-item IPIP-NEO (Johnson, 2014). The BFAS assess each of the Big Five personality domains (i.e., Extraversion, O/I, Agreeableness, Conscientiousness, and Neuroticism) and two associated aspects for each domain (including openness and intellect for the $\mathrm{O} / \mathrm{I}$ domain). Although all the domains were assessed, only the O/I aspects were utilised in this study. The IPIP-NEO is an open-access operationalization of the NEO-PI-R (Costa \& MacCrae, 1992) and assesses each of the Big Five domains and six lower-order facets for each domain. Only the O/I facets (i.e., Imagination, Artistic Interests, Adventurousness, Emotionality, Intellect, and Liberalism) were assessed for the current study.

Need for Cognition. Need for Cognition is the tendency to engage with and enjoy cognitively challenging tasks. This construct is either intellect by another name or a very close analogue (DeYoung, 2015). Need for Cognition was found to reside among the intellect constructs in the O/I simplex (DeYoung et al., 2012) and was found to be negatively associated with PPBS ratings (Pennycook et al., 2015). Thus, Need for Cognition is the one measure of openness or intellect found in both the O/I simplex and the seminal PPBS study, and was included in Study 1 accordingly. In line with the previous PPBS study, Need for Cognition was assessed using the Rationality section of the Rational-Experiential Inventory (REI-40; Pacini \& Epstein, 1999).

\section{Apophenia.}

Ontological Confusions. Ontological confusions are beliefs that confuse the nature (ontology) of different kinds of things. For example, the belief that, "It is possible to move 
material objects with only one's thoughts" incorrectly ascribes mental processes the ability to interact with physical things. A measure of ontological confusions was included as a measure of apophenia in the present research since ontological confusions were previously found to be positively associated with PPBS ratings (Pennycook et al., 2015).

Paranormal Beliefs. Paranormal beliefs include beliefs about witchcraft, superstition, spiritualism, extraordinary life forms, and precognition. Paranormal beliefs are a measure of apophenia (DeYoung et al., 2012) and were previously found to be positively associated with PPBS ratings (Pennycook et al., 2015). Paranormal beliefs include beliefs such as "Black cats bring bad luck".

Unusual Beliefs and Unusual Experiences. Unusual beliefs are odd and implausible beliefs such as "Can see into the future". Similarly, unusual experiences include experiences such as "Have had the feeling that I was someone else." These measures were similar to one previously used as a measure of apophenia (DeYoung et al., 2012). A Parallel Analysis Test (Horn, 1965) including all 14 items suggested that the measures were well represented by one factor $($ First Eigenvalue $=7.95$, second Eigenvalue $=1.20)$, so all 14 items were grouped together to yield an Unusual Beliefs and Experiences measure, which we treated as an additional measure of apophenia.

Statements. The study included six statement types, each comprised of 12 individual statements (see supplementary materials for a full list, available at: osf.io/cwbgv). Three of the statement types (PPBS, profound, and mundane statements) were the same types as those used by Pennycook and colleagues (2015). The remaining statement types were purely exploratory and did not differentiate well from the other statement types so were excluded 
from further analysis. Before reading the statements, participants were presented with the following instructions (adapted from Pennycook et al., 2015):

"We are interested in how people experience the profound. Below are a
series of statements taken from various sources (e.g., websites, quotations,
etc.). Please read each statement and take a moment to think about what it
might mean. Then please rate to what extent you agree that each statement is
'profound'. Profound means 'of deep meaning; of great and broadly
inclusive significance.",

Participants then rated the extent to which they agreed that each statement was "profound" using a 4-point Likert scale with the points: 1 (Strongly disagree), 2 (Slightly disagree), 3 (Slightly agree), 4 (Strongly agree). Average statement ratings for each statement type were computed, yielding three profundity-rating composites.

PPBS statements. Pennycook and colleagues (2015) sourced their PPBS statements (e.g. "Wholeness quiets infinite phenomena") from two internet sources (Pearce, n.d.; Williamson, 2012) and Chopra (2008-2018). The statements taken from the two internet sources were designed without concern for meaning, yet had the appearance of being intended to convey something profound due to their syntactic structure and the presence of profound-sounding words (Pennycook et al., 2015). As this seems to reflect influential conceptualisations of PPBS (e.g., Frankfurt, 2005), we decided that these sources were preferable to the tweets of Chopra (2008-2018), which are presumably intended to convey meaning. Additionally, the PPBS statements from Williamson (2012) were preferred to those of Pearce (n.d.) as the former are generally shorter and easier to read. Thus, the 10 PPBS 
statements from Williamson (2012) used in Pennycook and colleagues (2015) were employed and two additional statements were selected from Williamson (2012) to increase reliability and statistical power (Westfall, Kenny, \& Judd, 2014).

Profound statements. Profound statements (e.g. "The creative adult is the child who survived") were designed to be meaningful and profound. Ten of the profound statements were sourced from Pennycook and colleagues (2015; there labelled motivational quotations) with the remaining two being selected from a shortlist of items sourced from various quotation websites.

Mundane statements. Mundane statements (e.g., "Newborn babies require constant attention") were meaningful, yet mundane descriptions and observations. Ten of the mundane statements were sourced from Pennycook and colleagues (2015) with the remaining two devised by the authors.

Other measures. Several other measures were administered to participants but are unrelated to the present study aims and are not discussed further (see supplementary material for a full list, available at osf.io/cwbgv).

Procedure. All questionnaires and statements were presented using Qualtrics survey software (www.qualtrics.com) and were completed by participants in a laboratory. Participants completed several demographic questions, before rating the statements, which were presented in random order. The ICAR and Cognitive Reflection Test were presented third and fourth respectively, with the items within each measure presented in random order. The remaining questionnaires were presented in the following order: BFAS; IPIP-NEO; Need for Cognition; ontological confusions; paranormal belief; and unusual beliefs and experiences. The measures not used in the present research were presented last, alongside some additional demographic 
questions. After completing the questionnaire participants were fully debriefed regarding the aims of the study.

Data analysis. All data analysis was conducted using SPSS 25, unless otherwise specified. From the final sample of 140, there was just one missing value, which was imputed using SPSS's multiple imputation algorithm (Raghunathan, Lepkowski, Van Hoewyk, \& Solenberger, 2001). Given the very small amount of missing information $(\gamma<.001)$, three imputations were used. Pooled or average results are reported in all instances. Spearman correlations were employed due to violations of normality and the ordinal nature of the data.

Reliability. Revelle and Zinbarg (2009) recommend considering two aspects of reliability separately: internal consistency and general factor saturation. They define general factor saturation as the proportion of variance due to a general factor common to all test items. General factor saturation therefore measures the degree to which a test measures a single construct. They define internal consistency as the proportion of variance due to all common factors or, alternatively, how little of the variance is due to error. The $\omega_{\mathrm{t}}$ and $\omega_{\mathrm{h}}$ statistics are recommended to represent internal consistency and general factor saturation, respectively (McDonald, 1978, 1999; Revelle \& Zinbarg, 2009). However, these statistics are inaccurate for short scales, including the 4-item facet-level scales including in this $\mathrm{study}^{3}$, so maximum split-half reliability ( $\lambda_{4}$; Guttman, 1945; Jackson \& Agunwamba, 1977) and minimum split-half reliability $(\beta$; Revelle, 1979) were used in the present study as appropriate replacements for $\omega_{\mathrm{t}}$ and $\omega_{\mathrm{h}}$, respectively (Revelle \& Zinbarg, 2009). For scales

\footnotetext{
${ }^{3}$ Specifically, attempting to measure variance due to a general factor and variance due to several common factors (i.e., a total of 4 or more factors) with only 4 items results in under-identified models.
} 
of 20 items or fewer all split-half combinations were tested, but, due to computational limitations, samples of 100,000 split-half combinations were tested for longer scales. Cronbach's $\alpha$ was also included given most researchers' familiarity with this statistic.

The $\beta$ statistic was employed primarily to ensure that each measure-especially the un-validated statement type measures - had at least a moderate degree of general factor saturation, indicating measurement of a single construct. If the $\beta$ value was close to zero, it would indicate that participants' responses were due to two or more largely orthogonal factors (Revelle \& Zinbarg, 2009), which would make interpreting relationships with other measures problematic.

All reliability calculations were computed using the Psych package (Revelle, 2017) in RStudio (RStudio Team, 2016). Values of $\lambda_{4}$ above .70 were considered acceptable.

Profundity ratings for statement types. To determine differences in profundity ratings by statement type, a mixed effects model was estimated using Restricted Maximum Likelihood. The model, which resembled the Stimuli-within-Condition design discussed by Westfall and colleagues (2014), included profundity ratings as the dependent variable, and a fixed effects factor for statement type. As each statement could potentially elicit idiosyncratic differences in ratings, statements were included as a random factor. Similarly, individual participants could rate each statement type idiosyncratically, so unstructured random effects covariances between each statement type were computed. Planned comparisons were employed to compare profundity ratings for PPBS statements to the other two statement types.

This article is protected by copyright. All rights reserved. 
Confirming the Openness/Intellect Simplex model. A multidimensional scaling

model was estimated to examine whether the O/I simplex model described by DeYoung and colleagues (2012) could be recovered using the set of personality measures of this study. These were: Cognitive Ability, Cognitive Reflection, Need for Cognition, BFAS Openness and Intellect aspects, the six IPIP-NEO O/I facets, and the three apophenia measures. The model also included the PPBS composite to examine whether it could be accommodated on the simplex, adjacent to measures of apophenia. All measures were standardised prior to entry and models were estimated using the PROXCAL method (Busing, Commandeur, Heiser, Bandilla, \& Faulbaum, 1997) with Euclidean distances. Model fit was assessed with the Stress-I statistic, which indicates the impact of dimension reduction on distance between variables (Kruskal, 1964). Stress levels lower than 99\% of comparable models fitting random data were considered acceptable (Sturrock \& Rocha, 2000).

PPBS susceptibility: discrimination or response bias? Signal detection analysis was used to separate discrimination and response bias in terms of two parameters: $d$-prime (hereafter discrimination) and $c$ (response bias). In general discrimination measures the ability to distinguish signal from noise and response bias measures a threshold below which people will detect a signal ${ }^{4}$. In this case, discrimination measures the ability to distinguish profound from PPBS statements, and response bias measures the tendency to perceive a statement as profound. To facilitate this analysis, ratings of 3 or 4 (i.e., slightly agree or strongly agree) for profound statements were scored as "hits" (i.e., a profound statement

\footnotetext{
${ }^{4}$ The $\mathrm{c}$ parameter is alternatively measured as a response bias threshold below which people will detect a signal or a criterion above which people will detect a signal (i.e. $c_{1}=-c_{2}$; see Stanislaw \& Toderov, 1999). Following Snodgrass \& Corwin's (1988) formulation, we use the interpretation that enables c to be interpreted as response bias towards detecting signal.
} 
correctly identified as profound) and ratings of 3 or 4 for PPBS statements were scored as "false alarms" (i.e., a non-profound statement incorrectly identified as profound). The discrimination and response bias parameters were then calculated using formulae provided by Snodgrass and Corwin (1988).

\section{Results and Discussion}

Correlations among statement types and personality measures, along with descriptive statistics and measures of reliability, are reported in Tables 1 and 2. The Liberalism facet of $\mathrm{O} / \mathrm{I}$ failed to demonstrate acceptable internal consistency. In hindsight, one of the Liberalism items ("I tend to vote for liberal political candidates") may not have been appropriate for an Australian sample, where the more conservative of the two major parties is called the Liberal Party. This may have confused some participants, thereby reducing the reliability of the measure. General factor saturation was adequate for all measures, including, most importantly, our PPBS measure.

Table 1

Table 2

Profundity ratings for statement types. Statement types significantly predicted profundity ratings, $F(2,66.5)=41.03, p<.001$. Mean statement type ratings and $95 \%$ confidence intervals (CIs) are shown in Figure 2. Planned comparisons demonstrated that profound statements were rated as significantly more profound than PPBS statements, Mean Difference $=.61,95 \% \mathrm{CI}=[.42, .80], p<.001$, which were rated as significantly more 
profound than mundane statements, Mean Difference $=.44,95 \% \mathrm{CI}=[.21, .68], p<.001$. This order was as hypothesised and matched that found by Pennycook and colleagues (2015).

Figure 2

The random effects covariance matrix (Table 3) demonstrated that profundity ratings for mundane statements exhibited the highest variance, followed by PPBS statements and profound statements, and that only the covariance between profound and mundane statements was not statistically significant. Additionally, variance among statements was statistically significant, demonstrating the importance of using a mixed effects model $(\sigma=0.04,95 \% \mathrm{CI}$ $=[0.02,0.07]$, Wald $Z=3.74, p<.001)$. The residuals were close to normally distributed and the dependence between predicted values and residuals was minimal (excepting the dependency due to the violation of the assumption of continuous measurement), suggesting that analyses were robust to the non-parametric data. This is in line with Norman (2010), who argued that parametric methods are often acceptable (or even sometimes preferable) for use with non-parametric data.

Table 3

Associations of personality with profundity ratings. Correlations between statement types and personality measures are reported in Table 1. Two of the three apophenia constructs were positively correlated with profundity ratings for PPBS statements. Unusual Beliefs and Experiences was not correlated with PPBS ratings, but this was likely due to the extreme skew in scores for the former (29.3\% of participants rated every item as 1 [Strongly disagree]). These results suggest that PPBS is closely positively associated with apophenia. 
The results for the intelligence and intellect measures were less conclusive, however.

Although all these measures were negatively associated with PPBS, only the association with IPIP-NEO Intellect reached statistically significance. This lack of significant correlations was unexpected given the effect sizes of the negative associations consistently reported by Pennycook and colleagues (2015). However, all the intelligence and intellect measures recorded negative correlations with mundane statement ratings to a statistically significant degree, suggesting that those high in intellect were better able to recognise that the mundane statements were not profound 5 .

The results therefore partially matched expectations: The apophenia measures were generally positively correlated with PPBS ratings, as expected, but the intelligence and intellect measures were generally not correlated with PPBS ratings to a statistically significant degree, when we expected them to be significantly negatively related.

Confirming the Openness/Intellect Simplex Model. The solution of the simplex model is shown in Figure 3. The stress of the model was 0.19, which was well below the relevant critical value of 0.39 (Sturrock \& Rocha, 2000), suggesting that a unidimensional simplex model was an appropriate representation of the data.

As anticipated, Cognitive Ability lay at one extreme of the simplex, close to Cognitive Reflection, and the apophenia constructs lay at the opposite end. Measures of openness and intellect were distributed between these two extremes, with the openness

\footnotetext{
${ }^{5}$ These results were re-examined in a mixed effects model, which we conducted to: (a) confirm that the results were consistent with those found with the correlations; (b) to check that English language status did not overly influence the findings; and (c) to control for multiple tests by employing a single component for each group of constructs (i.e. intelligence, intellect, openness, and apophenia). English language status was not a significant predictor and the results were consistent with the conclusions drawn from the correlations. This analysis appears in the supplementary materials (available at osf.io/cwbgv).
} 
constructs relatively closer to the apophenia constructs (between Adventurousness and Emotionality) and the intellect constructs closer to the intelligence constructs (between BFAS Intellect and Need for Cognition). Thus, the order of our constructs matched the order found previously (DeYoung et al., 2012). The one exception was the location of Liberalism among the intellect measures. Although, a similar measure included in the original construction of the O/I simplex model (i.e., Values) was found to consistently lie toward the intelligence/intellect end of the spectrum (DeYoung et al., 2012), there has been some disagreement about the strength of the connection between cognitive styles (related to intellect) and conservatism/liberalism (Jost, Glaser, Kruglanski, \& Sulloway, 2003; Van Hiel, Onraet, \& De Pauw, 2010). However, the connection appears stronger for self-report measures (such as our intellect measures) than for behavioural measures (Van Hiel et al., 2010), suggesting that the location of Liberalism is consistent with previous literature. Importantly, the PPBS composite was located at the apophenia end of this simplex, suggesting that PBBS susceptibility can be usefully located in this structural model of personality and perhaps be considered an instance of apophenia.

Figure 3

PPBS susceptibility: discrimination or response bias? Some participants scored perfect hit rates, or no false alarms, which made calculating discrimination and response bias scores impossible for those individuals without an appropriate adjustment. Thus, hits and false alarms were corrected using the log-linear rule (Hautus, 1995). Note, that hit and false alarm rates were calculated with just 12 statements each, moderately biasing the log-linear 
rule towards zero (Hautus, 1995). However, as this would not affect rank-orders, Spearman correlations with these parameters should be relatively robust to such bias.

The pattern of correlations between the personality measures and discrimination was similar (only reversed) to the pattern with PPBS profundity ratings (Table 4): Ontological Confusions and Paranormal Beliefs were negatively correlated with discrimination, whereas IPIP-NEO Intellect was positively correlated with discrimination. On the other hand, Cognitive Reflection was positively correlated with discrimination, but not PPBS profundity ratings, and the reverse was true for the $\mathrm{O} / \mathrm{I}$ facets of Liberalism and Adventurousness. Interestingly, Adventurousness was negatively correlated with response bias, suggesting that its negative correlation with PPBS may have been driven by differences in response bias rather than discrimination. Overall, the measures that were correlated with PPBS were in general also correlated with discrimination and not with response bias, which suggests that the individual differences associated with rating PPBS statements as profound largely reflected one's capacity to discriminate the profound from the pseudo-profound, rather than response bias toward rating all statements as profound ${ }^{6}$.

Finally, discrimination was significantly negatively correlated with profundity ratings for mundane statements, $r=-.38, p<.001,95 \% \mathrm{CI}=[-.51,-.23]$, meaning that those who could better distinguish profound from PPBS statements were also superior at determining that mundane statements were not profound. This result is as expected and demonstrates the

\footnotetext{
${ }^{6}$ The results were re-examined in two regressions predicting discrimination and response bias, respectively. The regressions were conducted to: (a) confirm that the results were consistent with those found in the correlations; (b) to check that English language status did not overly influence the findings; and (c) to control for multiple tests. The results led to very similar conclusions to the correlations and appear in the supplementary materials (available at osf.io/cwbgv).
} 
validity of the discrimination measure. Conversely, response bias was not significantly correlated with profundity ratings of mundane statements, $r=.16, p=.055,95 \% \mathrm{CI}=[.00$, .32], demonstrating that response bias measured a bias towards finding seemingly profound statements profound more than a bias towards finding any statement profound.

\section{Table 4}

In summary, the results of Study 1 largely matched expectations: the apophenia measures were by and large positively correlated with PPBS profundity ratings; the O/I simplex closely matched the hypothesised order; the PPBS composite measure was located among the apophenia constructs; and individual differences in PPBS profundity ratings seemed to be primarily due to discrimination ability rather than response bias. However, contrary to the findings by Pennycook and colleagues (2015), the intelligence and intellect measures were generally not significantly correlated with PPBS ratings.

\section{Study 2}

Given the largely exploratory nature of Study 1, it was important to assess the robustness of our findings in a second replication study. Based on issues noted in Study 1, several minor amendments were made for Study 2 with the hope that these changes would increase the reliability of the findings. As we had gained a more precise understanding of our data and analyses, a substantially more comprehensive plan was pre-registered than for Study 1 (https://aspredicted.org/up4rw.pdf).

Perhaps the most unexpected observation in Study 1 was the lack of significant negative correlations between the intelligence measures and PPBS, which conflicts with previous findings (Pennycook et al., 2015). We wondered if the absence of significant effects 
may have been caused by inattentive responding. Thus, attention check questions were included in Study 2 to attempt to detect any inattentive participants. A question asking whether participants had responded honestly was also added to the end of the survey to further ensure the validity of responses.

Additionally, we wanted to reduce the bias caused by the adjustment for perfect hit and false alarm rates and increase the reliability of discrimination and response bias scores due to the relatively small number of statements in each category in Study 1 . We thus increased the number of PPBS and profound statements to 30 each. The Unusual Beliefs and Experiences Scale exhibited a floor effect in Study 1 so was replaced with Magical Ideation. The superfluous measures not analysed in Study 1 were omitted in Study 2.

The hypotheses were the same as in Study 1: We expected intelligence and intellect measures to be negatively associated with PPBS profundity ratings and apophenia measures to be positively associated; we expected the O/I simplex model to again be replicated; and we expected intelligence and intellect measures to be positively associated with discrimination and apophenia measures to be negatively associated. These predictions were pre-registered (https://aspredicted.org/up4rw.pdf).

\section{Method}

Participants. Two hundred and thirty-six participants were recruited from an undergraduate research participant pool at York University and were given partial course credit for their participation. The sample size was determined by convenience. All procedures received ethical approval at York University, and all participants provided informed consent. Twelve participants were excluded for failing to provide exit consent and a further 61 
participants were excluded for failing to correctly respond to at least one attention check question (see materials). A further 6 participants' responses were excluded for failing to provide responses to either $10 \%$ of the entire study or $20 \%$ of any one scale within the study.

The final sample included 157 participants (63.1\% female, $35.7 \%$ male, 1 other) aged 18 to 49 (Median $=19, \mathrm{IQR}=[18,20] ; 4$ unreported). Participants reported the culture with which they most identified, and our final sample consisted of $29.9 \%$ North Americans (Canadian or American), 17.2\% South Asian (Indian, Pakistani, etc.), 7.6\% African (South African, Moroccan, etc.), 7\% East Asian (Chinese, Japanese, etc.), and a small number in several other categories. Most participants reported English as their first language $(63.1 \%)$.

Materials. Measures were responded to on a 7-point Likert scale, ranging from 1 (Strongly Disagree) to 7 (Strongly Agree), unless otherwise specified. Four attention check questions were dispersed throughout the questionnaire (e.g., "Please click on strongly disagree and proceed to the next question").

Intelligence. As in Study 1, the intelligence end of the simplex was assessed with the ICAR (Condon \& Revelle, 2014) and the Cognitive Reflection Test (Toplak et al., 2014). Skipped questions were coded as incorrect for these measures.

Openness and Intellect. As in Study 1, the O/I aspects were assessed with the BFAS, but, unlike in Study 1, the IPIP-NEO was replaced with the O/I items from the BFI-2 (Soto \& John, 2016), which measures three aspects of O/I: Intellectual Curiosity, Creative Imagination, and Aesthetic Sensitivity. As we were primarily interested in assessing the relationships between profundity and O/I measures, remaining Big Five domains were not 
assessed. Also note that Need for Cognition was excluded from this study to help attenuate study length.

Apophenia. The Paranormal Belief measure used in Study 1 was retained for Study 2. However, Unusual Beliefs and Experiences was excluded due to the floor effect noted in Study 1, and was replaced with Magical Ideation (Eckblad \& Chapman, 1983). The latter measures beliefs in causal connections between things that cannot be related (e.g., "I have felt that there were messages for me in the way things were arranged, like in a store window").

The final measure of apophenia assessed ontological confusions. However, the measure used in Study 1 was replaced with the Core-Knowledge Confusions Scale (Lindeman \& Aarnio, 2007) to align with that used by Pennycook and colleagues (2015). The questions in the scale ask to what degree a series of metaphorically true, but literally false, statements (e.g., "Stars live in the sky") are metaphorically true, using a 5-point scale from 1 (only metaphorically true) to 5 (only literally true). Fillers were excluded for brevity.

Statements. To remedy the bias to discrimination and response bias scores, the number of profound and PPBS statements were increased to 30 each. The PPBS statements included those from Williamson (2012) and Pearce (n.d.) used by Pennycook and colleagues (2015) with additional statements from the two original sources to make up the numbers. The profound statements included those used in Study 1 with additional statements sourced from various quotation websites (see supplementary materials for the full list; available at osf.io/cwbgv). The scale used to assess the statement list was the same as used in Study 1. The other statement types included in Study 1 were dropped to make way for the additional statements in these two categories. 
Procedure. All questionnaires and statements were presented using Qualtrics survey software (www.qualtrics.com) and were completed by participants in a laboratory. After consenting to participate in the study, participants rated the profundity of the statements, which were presented randomly. Next, participants completed the ICAR, with items presented in a random order. The remaining questionnaires (Core-Knowledge Confusions, $\mathrm{O} / \mathrm{I}$ subscales of the BFAS, Openness subscale of the BFI-2, Cognitive Reflection Test, Paranormal Beliefs, and Magical Ideation) were presented in a random order with the items in each scale also presented in a random order. Finally, participants completed several demographic questions, including age, gender, native language, and years of English fluency. After completing the survey, participants were fully debriefed regarding the aims of the study and asked again if they consent to have their responses included in our data.

Data analysis. Data analyses were largely the same as for Study 1, with a few minor adjustments. Study 2 had a higher proportion of missing data (highest $\gamma=.013$ for Openness), so five imputations were used instead of three (Graham, Olchowski, \& Gilreath, 2007); the mixed effects model necessarily had two statement types instead of three; and the multidimensional scaling model included the collection of scales used in Study 2. The simplex model included Cognitive Ability, Cognitive Reflection, Intellect, Intellectual Curiosity, Openness, Creative Imagination, Aesthetic Sensitivity, Paranormal Belief, CoreKnowledge Confusions, Magical Ideation, and PPBS. Finally, the same procedure described in Study 1 was used to calculate discrimination and response bias scores, including the adjustment to account for perfect hits for some participants. 


\section{Results and Discussion}

Correlations among statement types and personality measures along with descriptive statistics and measures of reliability are reported in Tables 5 and 6. Intellectual Curiosity and Aesthetic Sensitivity were below the cut-off for internal consistency. General factor saturation was adequate for all measures. Magical Ideation avoided the floor effect noted for Unusual Beliefs and Experiences in Study 1, suggesting it was an appropriate replacement.

Table 5

Table 6

Profundity ratings for statement types. Statement types predicted profundity ratings, $F(1,86.7)=35.3, p<.001$, with profound statements $(M=3.12,95 \% \mathrm{CI}=[3.02$, 3.22]) rated as more profound than PPBS $(M=2.68,95 \% \mathrm{CI}=[2.57,2.79])$, Mean Difference $=0.44,95 \% \mathrm{CI}=[0.29,0.58], p<.001$.

The random effects covariance matrix (Table 7) demonstrated that profundity ratings for PPBS statements exhibited higher variance than profound statements, and that the covariance between statement types was positive and minimal, but statistically significant. Additionally, variance among statements (after controlling for variance due to statement type) was statistically significant, demonstrating the importance of using a mixed effects model ( $\sigma$ $=0.06,95 \% \mathrm{CI}=[0.04,0.09]$, Wald $Z=5.07, p<.001)$. The residuals were close to normally distributed and the dependence between predicted values and residuals was minimal (excepting the dependency due to the violation of the assumption of continuous measurement), suggesting that analyses were robust to the non-parametric data. 
Table 7

Associations of personality with profundity ratings. Correlations between PPBS and the personality measures are reported in Table 6. Contrary to Study 1, but consistent with predictions and the findings of Pennycook and colleagues (2015), Cognitive Ability and Cognitive Reflection were negatively correlated with PPBS to a statistically significant degree. Paranormal Belief was positively correlated with PPBS, also as expected. However, neither of the replacement apophenia measures was significantly correlated with PPBS, nor were Intellect and Intellectual Curiosity. Additionally, Aesthetic Sensitivity was negatively correlated with PPBS, when we did not expect it to be associated. ${ }^{7}$

Like Study 1, the results partially matched expectations. However, unlike in Study 1, where the apophenia measures were by and large correlated with PPBS and the intelligence measures were not, in Study 2, the intelligence measures were correlated with PPBS and two of the three apophenia measures were not. The intellect measures were also not correlated with PPBS ratings to a statistically significant degree, largely consistent with Study 1.

Confirming the Openness/Intellect Simplex Model. The simplex solution is shown in Figure 4. The stress of the model was 0.17, which was well below the relevant critical value of 0.33 (Sturrock \& Rocha, 2000), suggesting that a unidimensional simplex model was an appropriate representation of the data.

\footnotetext{
${ }^{7}$ As in Study 1, these results were re-examined in mixed effects models, which we conducted to: (a) confirm that the results were consistent with those found with the correlations; (b) to check that English language status did not overly influence the findings; and (c) to control for multiple tests by employing a single component for each group of constructs (i.e. intelligence, openness and intellect, and apophenia). English language status was not a significant predictor and the results were consistent with the conclusions drawn from the correlations. This analysis appears in the supplementary materials (available at osf.io/cwbgv).
} 
Figure 4

The solution was similar though not identical to that reported in Study 1 and by DeYoung and colleagues (2012). The openness and intellect constructs were grouped together, with Cognitive Ability and Cognitive Reflection at one extreme and the apophenia measures at the other. In this sample, Cognitive Reflection had become the more extreme measure at the intelligence end of the simplex, which seems likely due to the floor effect observed in the measure in Study 2 that was not observed in Study $1 .{ }^{8}$ Additionally, PPBS was again located with the apophenia measures, confirming its place among these measures. Thus, the data provided a close if imperfect replication of DeYoung and colleagues' (2012) O/I simplex model.

PPBS susceptibility: discrimination or response bias? Consistent with expectations, Cognitive Ability and Cognitive Reflection were positively correlated with discrimination, mirroring the simple correlations with PPBS ratings (Table 8). However, contrary to expectations, neither of the intellect measures was significantly positively correlated with discrimination. Additionally, none of the intelligence and intellect measures were significantly correlated with response bias. Thus, intelligence measures were significantly correlated with discrimination in three of four instances across both studies and were never significantly correlated with response bias. These results suggest that higher intelligence enables people to better distinguish PPBS statements from legitimately profound

\footnotetext{
${ }^{8}$ An anonymous reviewer is thanked for this observation.
} 
statements, which is a plausible explanation for the negative relation between the intelligence measures and PPBS profundity ratings.

Table 8

Consistent with expectations, Core-Knowledge Confusions was significantly negatively correlated with discrimination, although, contrary to expectations, Paranormal Belief and Magical Ideation were not. Paranormal Belief was, however, positively correlated with response bias. This finding suggests that response bias may play some role in explaining why people higher in apophenia perceive PPBS statements as more profound than those low in apophenia. However, the result conflicted with that of Study 1 where Paranormal Belief and Ontological Confusions were negatively correlated with discrimination and not response bias. Regardless, Paranormal Belief was the only significant correlate of response bias in Study 2 and Adventurousness was the only significant correlate of response bias in Study 1, suggesting that, consistent with expectations, discrimination is more important than response bias in explaining the relationships between $\mathrm{O} / \mathrm{I}$ personality measures and PPBS ratings. ${ }^{9}$

In sum, the results generally matched predictions based on the results of Study 1 and those reported by Pennycook and colleagues (2015): The intelligence measures were significantly negatively correlated with PPBS ratings and this was likely due to differences in ability to distinguish the profound from the pseudo-profound. The O/I simplex reported in Study 1 and by DeYoung and colleagues (2012) was approximately replicated, albeit

\footnotetext{
${ }^{9}$ The results were re-examined in two regressions predicting discrimination and response bias, respectively. The regressions were conducted to: (a) confirm that the results were consistent with those found in the correlations; (b) to check that English language status did not overly influence the findings; and (c) to control for multiple tests. The results led to very similar conclusions to the correlations and appear in the supplementary materials (available at osf.io/cwbgv).
} 
imperfectly, and a simplex model was adequate for describing relations among the O/I constructs. Additionally, the PPBS composite measure was located among the apophenia measures as expected and found in Study 1. Contrary to expectations, however, only Paranormal Belief of the apophenia measures was significantly correlated with PPBS, and its correlation appeared more to do with a bias towards perceiving profundity generally, rather than a relatively poor ability to distinguish the profound from the pseudo-profound. Finally, the intellect measures were not correlated with PPBS, which was broadly consistent with Study 1 , but contrary to expectations.

\section{General Discussion}

Both of the present studies aimed to: (1) replicate the correlates of PPBS profundity ratings reported by Pennycook and colleagues (2015); (2) determine whether the pattern of associations could be organised in terms of the $\mathrm{O} / \mathrm{I}$ simplex model identified by DeYoung and colleagues (2012); and (3) discover if the individual differences in PPBS profundity ratings were primarily due to differences in discrimination or response bias. On the whole, these goals were successful in both studies.

First, the correlates of PPBS profundity ratings were broadly consistent with previous findings. In all cases, the direction of the correlations was as expected, with Paranormal Belief positively correlated with PPBS profundity ratings in both studies. Additionally, Ontological Confusions was positively correlated with PPBS ratings in Study 1 and the intelligence measures were negatively correlated with PPBS ratings in Study 2. Together these results suggest that the associations discovered by Pennycook and colleagues (2015) are reasonably robust. However, the inconsistency in findings for the present studies suggest that 
the true effect sizes may be somewhat lower than previously reported or that the true effect sizes for the PPBS statements are lower for our response scale than for Pennycook and colleagues' (2015) version.

The results were also consistent with DeYoung and colleagues' (2012) finding that the $\mathrm{O} / \mathrm{I}$ domain is well described by a simplex. In both studies, a simplex model fit the data well, with intelligence at one end, apophenia at the other end, and the remaining constructs falling in between. Additionally, a PPBS aggregate measure was in each case located near the apophenia measures, supporting our suggestion that it may be considered a specific instance of apophenia (i.e., detecting meaning where none exists). These results suggest that the O/I simplex is a good description of the O/I domain and that PPBS profundity ratings are closely related to the $\mathrm{O} / \mathrm{I}$ simplex.

Finally, individual differences in profundity ratings of PPBS statements could be primarily explained by the ability to discriminate the profound from the pseudo-profound, more so than a tendency to endorse profundity (i.e., response bias). Measures of intelligence tended to be positively associated with discrimination and not associated with response bias. The results were slightly less clear for the measures of apophenia. In three of six instances apophenia measures were negatively associated with discrimination to a statistically significant degree, suggesting that diminished discrimination ability plays an important role in the association between apophenia and PPBS profundity ratings. However, in Study 2 only one apophenia measure was significantly negatively correlated with discrimination and another significantly positively correlated with response bias. Thus, response bias may also play some role in explaining higher PPBS profundity ratings for those scoring highly on 
apophenia measures. Nevertheless, across both studies only two measures were significantly correlated with response bias-Adventurousness in Study 1 and Paranormal Belief in Study 2-suggesting, as expected, that differences in discrimination generally played the larger role in explaining why people differ in how profound they saw the PPBS statements.

\section{Intelligence as Protection Against Apophenia}

The identification of PPBS profundity ratings as a plausible measure of apophenia is perhaps a first step to clarifying a theory posited by DeYoung and colleagues (2012). They proposed that openness may be generally beneficial to the degree that it helps people notice patterns and generate ideas that are useful. However, high levels of openness may also be maladaptive, given that positive schizotypy is a risk factor for psychosis (e.g., Miller et al., 2002; Nettle, 2006) and apophenia is closely related to positive schizotypy. If intelligence can act as a protection against apophenia, then it may enable higher levels of openness and its attendant benefits while mitigating the risk of psychosis. Thus, given the O/I simplex model includes intelligence as a facet of intellect, DeYoung and colleagues (2012) argued that the covariance between openness and intellect may have been evolutionarily selected together precisely to avoid the maladaptive drift towards apophenia and psychosis.

Within such a theory, openness and intellect are presented as separable constructs that nevertheless form a broader factor due to some common adaptive mechanism. This theory is supported by evidence that openness and intellect form separate factors if a sufficiently broad spectrum of openness and intellect items are measured and if enough factors are extracted (DeYoung et al., 2016; DeYoung et al., 2012). Nevertheless, DeYoung and colleagues (2012) could not demonstrate that intelligence acts as protection against apophenia because their 
measures of apophenia did not have correct and incorrect responses. Thus, even if more intelligent participants tended to endorse apophenia items less frequently, there was no way to discover whether this was due to differences in discrimination or response bias. Yet the hypothesised mechanism for the connection between openness and intellect requires that intelligence enable the benefits of high openness while simultaneously reducing its costs (i.e. apophenia). Such is only possible if intelligence aids discrimination of true novelty and insight from apophenia, rather than reducing both apophenia and insight jointly (i.e. reducing response bias).

By comparing profundity ratings for PPBS statements to those of profound statements, we could compute discrimination scores and determine that those scoring higher on measures of intelligence were typically superior at discriminating between the two statement types.

Thus, those scoring higher on intelligence measures tended to be fooled by PPBS statements less frequently precisely because they were superior at detecting that such statements were not profound, rather than because they did not tend to find statements profound in general. This data helps to strengthen the idea that intelligence does indeed act as protection against at least one type of apophenia. Although this finding did not generalise to intellect, the present research may provide a method for beginning to tease apart the connection between apophenia and intelligence, and openness and intellect more generally.

\section{Limitations and Future Directions}

Any inferences drawn from the studies presented in this paper rely on the assumption that PPBS is indeed a measure of apophenia. Although PPBS seems to be a measure of apophenia by definition, it was only correlated with other measures of apophenia at an 
average of .18 across the two studies, which would be comparatively low if measuring the same underlying construct. These relatively low correlations preclude any firm conclusions about how PPBS relates to previous research on apophenia and positive schizotypy. Of course, these correlations may have been attenuated by the different methods used to assess PPBS and apophenia. Alternatively, responses to PPBS statements may have been more strongly affected by careless responding than other measures of apophenia, given the difficulty in trying to determine what PPBS statements might mean. Similarly, one might wonder if PPBS is a proxy of intelligence, which might explain its relatively low correlations with the apophenia measures. However, PPBS was not strongly correlated with either measure of intelligence in our two studies (correlations no larger -.20), so it seems more likely that PPBS susceptibility is a consequence of low intelligence rather than a direct proxy of it. Future research on the processes involved in responding to PPBS and how these are related to apophenia, positive schizotypy, and intelligence is required to better understand the relationship between PPBS and apophenia.

A first step in this task might involve determining how the illusory meaning of PPBS affected the relationship with other measures of apophenia. Specifically, the difficulty of figuring out what PPBS statements might mean may have increased the prevalence of careless responding relative to other measures in the surveys and thereby attenuated correlations. A type of statement known as 'deepities'—statements that are either true but trite, or seemingly profound but in fact false (Dennett, 2014) — may offer a means of testing the relationship between illusory meaning and profundity ratings. Consider the deepity, "love is just a word". The word "love" is, by definition, just a word; however, the concept "love" is 
clearly not just a word. In this case, the deepity rests on an equivocation of the meaning of "love" to suggest a profound, but false, interpretation. Such statements share a close resemblance to PPBS: They are both pseudo-profound and are syntactically correct. However, unlike PPBS, deepities are also meaningful. Thus, investigating whether profundity ratings for such statements behave similarly to those for PPBS would enable some tentative conclusions regarding the relationship between the illusory meaning of PPBS and the relatively low correlations with traditional apophenia constructs as observed in the present studies.

Finally, it should be acknowledged that both of our studies recruited university student samples, which are not representative of the wider population regarding several dimensions (e.g., sex ratio, age, socio-economic status). As a result, caution should be exercised in generalizing these results beyond similar student populations. On the other hand, the two samples were recruited from different Western countries with different ethnic compositions and yet produced similar results. This suggests that those results that were consistent across the two samples may be robust to these factors. Moreover, our findings were broadly in line with those of Pennycook and colleagues (2015), who did not rely on student samples.

\section{Conclusion}

To echo Pennycook and colleagues' (2015) quotation of Frankfurt (2005): “One of the most salient features of our culture is that there is so much bullshit." In many arenas of modern life — from advertising campaigns to government policy to corporate strategic plans-conveying information that creates the illusion of substance is more important than the veracity of what is being conveyed. Thus, much of the apparently important and 
meaningful information we encounter and consume is likely to be misleading or even vacuous.

In the present research, we built on Pennycook and colleagues' (2015) seminal research into PPBS susceptibility in several ways. First, we provided the first independent replications of the correlates of PPBS susceptibility. Second, we demonstrated that profundity ratings for PPBS statements can be parsimoniously understood through the lens of the O/I simplex model. Measures of apophenia were typically associated with higher profundity ratings for these statements, whereas intelligence measures were typically associated with lower ratings. Our results furthermore confirm that PPBS susceptibility itself may constitute a specific instance of apophenia, given its location alongside other apophenia measures on the O/I simplex. Third, we provided a more rigorous examination of the decision mechanisms driving individual differences in PPBS susceptibility by employing signal detection analyses. This revealed that associations with PPBS profundity ratings were typically due to differences in participants' ability to distinguish profound statements from pseudo-profound statements rather than simply a difference in biases towards finding statements profound generally. The association with discrimination was particularly apparent for measures of intelligence.

More speculatively, we also further developed the hypothesis that intelligence may act as a protective mechanism against apophenia. Although it would be premature to conclude that intellect is associated with openness in part because it acts as a protection against apophenia and related phenomena, the present research provides a step down this path by noting that PPBS profundity ratings may be thought of as an ability-based test of apophenia 
and that intelligence is protective against mistaking PPBS for truly profound statements. To paraphrase both DeYoung and colleagues (2012) and Pennycook and colleagues (2015): we hope that this hypothesis is not an instance of apophenia, but rather that it is meaningful, if not profound.

\section{Funding}

Study 2 was supported in part by a grant awarded by the Social Sciences and Humanities Research Council of Canada to RAM (\#435-2017-1030). 


\section{References}

Ackerman, P. L., \& Heggestad, E. D. (1997). Intelligence, personality, and interests: Evidence for overlapping traits. Psychological bulletin, 121(2), 219. doi:10.1037//0033-2909.121.2.219

Busing, F., Commandeur, J. J., Heiser, W. J., Bandilla, W., \& Faulbaum, F. (1997). PROXSCAL: A multidimensional scaling program for individual differences scaling with constraints. Softstat, 97, 67-74.

Chopra, D. (2008-2018). Deepak Chopra. Retrieved from https://twitter.com/deepakchopra

Condon, D. M., \& Revelle, W. (2014). The international cognitive ability resource: Development and initial validation of a public-domain measure. Intelligence, 43, 52 64. doi:10.1016/j.intell.2014.01.004

Costa, P. T., \& MacCrae, R. R. (1992). Revised NEO personality inventory (NEO PI-R) and NEO five-factor inventory (NEO-FFI): Professional manual: Psychological Assessment Resources.

Dalton, C. (2016). Bullshit for you; transcendence for me. A commentary on "On the reception and detection of pseudo-profound bullshit". Judgment and Decision Making, 11(1), 121-122.

Dennett, D. C. (2014). Intuition Pumps And Other Tools for Thinking. New York, NY: W. W. Norton \& Company.

This article is protected by copyright. All rights reserved. 
DeYoung, C. G. (2011). Intelligence and personality. In R. J. Sternberg \& S. B. Kaufman (Eds.), The Cambridge Handbook of Intelligence (pp. 711-737). New York, NY: Cambridge University Press.

DeYoung, C. G. (2015). Openness/intellect: A dimension of personality reflecting cognitive exploration. In APA handbook of personality and social psychology, Volume 4: Personality processes and individual differences. (pp. 369-399). Washington, DC, US: American Psychological Association.

DeYoung, C. G., Carey, B. E., Krueger, R. F., \& Ross, S. R. (2016). Ten aspects of the Big Five in the Personality Inventory for DSM-5. Personality Disorders: Theory, Research, and Treatment, 7(2), 113. doi:10.1037/per0000170

DeYoung, C. G., Grazioplene, R. G., \& Peterson, J. B. (2012). From madness to genius: The Openness/Intellect trait domain as a paradoxical simplex. Journal of Research in Personality, 46(1), 63-78. doi:10.1016/j.jrp.2011.12.003

DeYoung, C. G., Quilty, L. C., \& Peterson, J. B. (2007). Between facets and domains: 10 aspects of the Big Five. Journal of personality and social psychology, 93(5), 880-896. doi:10.1037/0022-3514.93.5.880

Eckblad, M., \& Chapman, L. J. (1983). Magical ideation as an indicator of schizotypy. Journal of consulting and clinical psychology, 51(2), 215. doi:10.1037/0022006X.51.2.215

Fraley, R. C., \& Marks, M. J. (2007). The null hypothesis significance testing debate and its implications for personality research. In R. W. Robins, R. C. Fraley, \& R. F. Krueger 
(Eds.), Handbook of Research Methods in Personality Psychology (pp. 149-169). New York, NY: Guilford Press.

Frankfurt, H. G. (1986). On bullshit. Raritan: A Quarterly Review, 6(2), 81-100.

Frankfurt, H. G. (2005). On Bullshit. Princeton, NJ: Princeton University Press.

Goldberg, L. R. (1990). An alternative" description of personality": the big-five factor structure. Journal of personality and social psychology, 59(6), 1216. doi:10.1037/0022-3514.59.6.1216

Graham, J. W., Olchowski, A. E., \& Gilreath, T. D. (2007). How Many Imputations are Really Needed? Some Practical Clarifications of Multiple Imputation Theory. Prevention Science, 8(3), 206-213. doi:10.1007/s11121-007-0070-9

Green, D. M., \& Swets, J. A. (1966). Signal Detection Theory and Psychophysics. Oxford, England: John Wiley.

Guttman, L. (1945). A basis for analyzing test-retest reliability. Psychometrika, 10(4), 255282. doi:10.1007/bf02288892

Hautus, M. J. (1995). Corrections for extreme proportions and their biasing effects on estimated values ofd'. Behavior Research Methods, Instruments, \& Computers, 27(1), 46-51. doi:10.3758/bf03203619

Horn, J. L. (1965). A rationale and test for the number of factors in factor analysis. Psychometrika, 30(2), 179-185. doi:10.1007/bf02289447

Jackson, P. H., \& Agunwamba, C. C. (1977). Lower bounds for the reliability of the total score on a test composed of non-homogeneous items: I: Algebraic lower bounds. Psychometrika, 42(4), 567-578. doi:10.1007/bf02295979

This article is protected by copyright. All rights reserved. 
Johnson, J. A. (2014). Measuring thirty facets of the Five Factor Model with a 120-item public domain inventory: Development of the IPIP-NEO-120. Journal of Research in Personality, 51, 78-89. doi:10.1016/j.jrp.2014.05.003

Jost, J. T., Glaser, J., Kruglanski, A. W., \& Sulloway, F. J. (2003). Political conservatism as motivated social cognition. In: American Psychological Association.

Kruskal, J. B. (1964). Multidimensional scaling by optimizing goodness of fit to a nonmetric hypothesis. Psychometrika, 29(1), 1-27. doi:10.1007/bf02289565

Kwapil, T. R., Barrantes-Vidal, N., \& Silvia, P. J. (2008). The Dimensional Structure of the Wisconsin Schizotypy Scales: Factor Identification and Construct Validity. Schizophrenia bulletin, 34(3), 444-457. doi:10.1093/schbul/sbm098

Lindeman, M., \& Aarnio, K. (2007). Superstitious, magical, and paranormal beliefs: An integrative model. Journal of Research in Personality, 41(4), 731-744. doi:10.1016/j.jrp.2006.06.009

Lobato, E., Mendoza, J., Sims, V., \& Chin, M. (2014). Examining the relationship between conspiracy theories, paranormal beliefs, and pseudoscience acceptance among a university population. Applied Cognitive Psychology, 28(5), 617-625. doi:10.1002/acp.3042

Markon, K. E., Krueger, R. F., \& Watson, D. (2005). Delineating the Structure of Normal and Abnormal Personality: An Integrative Hierarchical Approach. Journal of personality and social psychology, 88(1), 139-157. doi: 10.1037/0022-3514.88.1.139

This article is protected by copyright. All rights reserved. 
McDonald, R. P. (1978). Generalizability in Factorable Domains: "Domain Validity and Generalizability"1. Educational and Psychological Measurement, 38(1), 75-79. doi:doi:10.1177/001316447803800111

McDonald, R. P. (1999). Test Theory: A Unified Treatment. Mahwah, NJ: Lawrence Erlbaum Associates.

Miller, P., Byrne, M., Hodges, A., Lawrie, S. M., Owens, D. G. C., \& Johnstone, E. C. (2002). Schizotypal components in people at high risk of developing schizophrenia: early findings from the Edinburgh High-Risk Study. The British Journal of Psychiatry, 180(2), 179-184. doi:10.1192/bjp.180.2.179

Nettle, D. (2006). The evolution of personality variation in humans and other animals. American Psychologist, 61(6), 622. doi:10.1037/0003-066X.61.6.622

Norman, G. (2010). Likert scales, levels of measurement and the "laws" of statistics. Advances in Health Sciences Education, 15(5), 625-632. doi:10.1007/s10459-010$9222-y$

Pacini, R., \& Epstein, S. (1999). The relation of rational and experiential information processing styles to personality, basic beliefs, and the ratio-bias phenomenon. Journal of personality and social psychology, 76(6), 972-987. doi:10.1037/00223514.76.6.972

Pearce, S. (n.d.). New Age Bullshit Generator. Retrieved from http://sebpearce.com/bullshit/ Pennycook, G., Cheyne, J. A., Barr, N., Koehler, D. J., \& Fugelsang, J. A. (2015). On the reception and detection of pseudo-profound bullshit. Judgment and Decision Making, 10(6), 549-563.

This article is protected by copyright. All rights reserved. 
Pennycook, G., Cheyne, J. A., Barr, N., Koehler, D. J., \& Fugelsang, J. A. (2016). It's still bullshit: Reply to Dalton (2016). Judgment and Decision Making, 11(1), 123.

Raghunathan, T. E., Lepkowski, J. M., Van Hoewyk, J., \& Solenberger, P. (2001). A multivariate technique for multiply imputing missing values using a sequence of regression models. Survey methodology, 27(1), 85-96.

Revelle, W. (1979). Hierarchical Cluster Analysis And The Internal Structure Of Tests. Multivariate Behavioral Research, 14(1), 57-74. doi:10.1207/s15327906mbr1401_4

Revelle, W. (2017). psych: Procedures for Psychological, Psychometric, and Personality Research. Evanston, IL: Northwestern University. Retrieved from https://CRAN.Rprojects.org/package $=$ psych

Revelle, W., \& Zinbarg, R. E. (2009). Coefficients Alpha, Beta, Omega, and the glb: Comments on Sijtsma. Psychometrika, 74(1), 10. doi:10.1007/s11336-008-9102-z

RStudio Team. (2016). RStudio: Integrated Development for R (Version 1.0.136). Boston, MA: RStudio. Retrieved from http://rstudio.com/

Snodgrass, J. G., \& Corwin, J. (1988). Pragmatics of measuring recognition memory: Applications to dementia and amnesia. Journal of Experimental Psychology: General, 117(1), 34-50. doi:10.1037/0096-3445.117.1.34

Soto, C. J., \& John, O. P. (2016). The next Big Five Inventory (BFI-2): Developing and assessing a hierarchical model with 15 facets to enhance bandwidth, fidelity, and predictive power. Journal of personality and social psychology, 113(1), 27. doi:10.1037/pspp0000096

This article is protected by copyright. All rights reserved. 
Stanislaw, H., \& Todorov, N. (1999). Calculation of signal detection theory measures. Behavior Research Methods, Instruments, \& Computers, 31(1), 137-149. doi:10.3758/bf03207704

Sternberg, R. (1999). The theory of successful intelligence. Review of general psychology, 3(4), 292-316.

Sturrock, K., \& Rocha, J. (2000). A multidimensional scaling stress evaluation table. Field Methods, 12(1), 49-60. doi:10.1177/1525822x0001200104

Toplak, M. E., West, R. F., \& Stanovich, K. E. (2014). Assessing miserly information processing: An expansion of the Cognitive Reflection Test. Thinking \& Reasoning, 20(2), 147-168. doi:10.1080/13546783.2013.844729

Van Hiel, A., Onraet, E., \& De Pauw, S. (2010). The Relationship Between Social-Cultural Attitudes and Behavioral Measures of Cognitive Style: A Meta-Analytic Integration of Studies. Journal of Personality, 78(6), 1765-1800. doi:10.1111/j.14676494.2010.00669.x

Vollema, M. G., \& van den Bosch, R. J. (1995). The multidimensionality of schizotypy. Schizophrenia bulletin, 21(1), 19-31. doi:10.1093/schbul/21.1.19

Westfall, J., Kenny, D. A., \& Judd, C. M. (2014). Statistical power and optimal design in experiments in which samples of participants respond to samples of stimuli. Journal of Experimental Psychology: General, 143(5), 2020-2045. doi:10.1037/xge0000014

Williamson, T. (2012). Wisdom of Chopra. Retrieved from http://wisdomofchopra.com/index.php

Table 1

This article is protected by copyright. All rights reserved. 
Descriptive Statistics and Reliability Estimates of Each Statement Type, and Correlations Among Statement Types and Between Statement Types and Personality

\begin{tabular}{|c|c|c|c|c|c|c|}
\hline \multirow{2}{*}{ Statement Types } & \multicolumn{2}{|r|}{ PPBS } & \multicolumn{2}{|c|}{ Profound } & \multicolumn{2}{|c|}{ Mundane } \\
\hline & & & & & & \\
\hline Profound & .32 & {$[.16, .46]$} & & & & \\
\hline Mundane & .26 & {$[.10, .41]$} & .06 & {$[-.11, .22]$} & & \\
\hline \multicolumn{7}{|c|}{ Intelligence and Intellect Measures } \\
\hline Cognitive Ability & -.13 & {$[-.29, .03]$} & -.09 & {$[-.25, .08]$} & -.17 & {$[-.33,-.01]$} \\
\hline Cognitive Reflection & -.10 & {$[-.25, .08]$} & -.03 & {$[-.20, .13]$} & -.32 & {$[-.47,-.17]$} \\
\hline Need for Cognition & -.09 & {$[-.26, .07]$} & -.02 & {$[-.19, .14]$} & -.25 & {$[-.40,-.09]$} \\
\hline BFAS Intellect & -.13 & {$[-.29, .04]$} & .00 & {$[-.16, .17]$} & -.25 & {$[-.40,-.09]$} \\
\hline IPIP Intellect & -.19 & {$[-.34,-.02]$} & .00 & {$[-.17, .17]$} & -.33 & {$[-.47,-.18]$} \\
\hline Liberalism & -.17 & {$[-.33,-.00]$} & -.05 & {$[-.22, .11]$} & -.20 & {$[-.35,-.03]$} \\
\hline \multicolumn{7}{|l|}{ Openness Measures } \\
\hline Openness & -.05 & {$[-.21, .12]$} & .14 & {$[-.03, .30]$} & -.17 & {$[-.33,-.01]$} \\
\hline Imagination & .01 & {$[-.16, .17]$} & .12 & {$[-.05, .28]$} & -.09 & {$[-.25, .08]$} \\
\hline Artistic Interests & .00 & {$[-.16, .17]$} & .15 & {$[-.01, .31]$} & -.21 & {$[-.36,-.04]$} \\
\hline Emotionality & .02 & {$[-.15, .18]$} & .22 & {$[.05, .37]$} & -.08 & {$[-.24, .09]$} \\
\hline Adventurousness & -.22 & {$[-.37,-.06]$} & -.22 & {$[-.37,-.06]$} & -.06 & {$[-.23, .10]$} \\
\hline \multicolumn{7}{|l|}{ Apophenia Measures } \\
\hline Ontological Confusions & .29 & {$[.13, .44]$} & .07 & {$[-.09, .24]$} & .18 & {$[.02, .34]$} \\
\hline Paranormal Belief & .23 & {$[.07, .38]$} & .04 & {$[-.13, .21]$} & .11 & {$[-.05, .27]$} \\
\hline $\begin{array}{l}\text { Unusual Beliefs \& } \\
\text { Experiences }\end{array}$ & .11 & {$[-.05, .27]$} & .00 & {$[-.16, .17]$} & .07 & {$[-.10, .23]$} \\
\hline Mean & & 2.66 & & 3.27 & & 2.21 \\
\hline $\mathrm{SD}$ & & 0.54 & & 0.37 & & 1.05 \\
\hline Skewness & & -0.81 & & -0.80 & & 0.23 \\
\hline Kurtosis & & 0.57 & & 1.68 & & -1.64 \\
\hline Max. Split-Half Reliability & & .90 & & .81 & & .98 \\
\hline Min. Split-Half Reliability & & .77 & & .54 & & .95 \\
\hline Alpha & & .85 & & .69 & & .97 \\
\hline
\end{tabular}

Note. Bold indicates $p<.05 .95 \%$ Confidence Intervals in brackets. 
Table 2

Correlations, Descriptive Statistics, and Reliability Estimates of the Personality Scales

\begin{tabular}{|c|c|c|c|c|c|c|c|c|c|c|c|c|c|c|c|}
\hline & & 1 & 2 & 3 & 4 & 5 & 6 & 7 & 8 & 9 & 10 & 11 & 12 & 13 & 14 \\
\hline & Intelligence and Intellec & ures & & & & & & & & & & & & & \\
\hline 1 & Cognitive Ability & & & & & & & & & & & & & & \\
\hline 2 & Cognitive Reflection & .46 & & & & & & & & & & & & & \\
\hline 3 & Need for Cognition & .19 & .35 & & & & & & & & & & & & \\
\hline 4 & BFAS Intellect & .18 & .31 & .80 & & & & & & & & & & & \\
\hline 5 & IPIP Intellect & .20 & .20 & .69 & .73 & & & & & & & & & & \\
\hline \multirow[t]{2}{*}{6} & Liberalism & .12 & .17 & .20 & .17 & .38 & & & & & & & & & \\
\hline & Openness Measures & & & & & & & & & & & & & & \\
\hline 7 & Openness & .01 & -.01 & .32 & .40 & .55 & .28 & & & & & & & & \\
\hline 8 & Imagination & -.01 & -.08 & .09 & .20 & .28 & .23 & .53 & & & & & & & \\
\hline 9 & Artistic Interests & -.07 & -.01 & .33 & .38 & .53 & .18 & .86 & .41 & & & & & & \\
\hline 10 & Emotionality & -.03 & -.04 & .08 & .09 & .19 & .00 & .43 & .37 & .36 & & & & & \\
\hline \multirow[t]{2}{*}{11} & Adventurousness & .03 & .05 & .35 & .34 & .43 & .32 & .38 & .13 & .33 & .08 & & & & \\
\hline & Apophenia Measures & & & & & & & & & & & & & & \\
\hline 12 & Ontological Confusions & -.23 & -.21 & -.23 & -.25 & -.21 & -.18 & .06 & .11 & .10 & .09 & -.01 & & & \\
\hline 13 & Paranormal Belief & -.18 & -.10 & -.22 & -.22 & -.19 & -.16 & -.03 & .10 & .01 & -.05 & -.01 & .87 & & \\
\hline 14 & $\begin{array}{l}\text { Unusual Beliefs \& } \\
\text { Experiences }\end{array}$ & -.08 & .05 & -.14 & -.12 & -.07 & .01 & .07 & .23 & .05 & .03 & .17 & .58 & .68 & \\
\hline & Mean & 10.08 & 3.15 & 3.48 & 3.47 & 3.51 & 3.23 & 3.87 & 3.76 & 3.87 & 3.91 & 3.07 & 2.55 & 2.06 & 1.58 \\
\hline & SD & 3.00 & 2.17 & 0.58 & 0.64 & 0.86 & 0.66 & 0.66 & 0.84 & 0.85 & 0.77 & 0.80 & 0.87 & 0.78 & 0.71 \\
\hline & Skewness & -0.18 & 0.12 & -0.08 & -0.07 & -0.28 & 0.46 & -0.14 & -0.30 & -0.69 & -0.44 & 0.08 & -0.06 & 0.46 & 1.45 \\
\hline & Kurtosis & -0.18 & -1.20 & -0.04 & -0.45 & -0.57 & 0.66 & -0.89 & -0.41 & 0.00 & -0.36 & -0.24 & -0.88 & -0.73 & 1.56 \\
\hline
\end{tabular}

This article is protected by copyright. All rights reserved. 


\begin{tabular}{|c|c|c|c|c|c|c|c|c|c|c|c|c|c|c|}
\hline Max. Split-Half Reliability & 0.83 & 0.80 & 0.95 & 0.88 & 0.80 & 0.50 & 0.87 & 0.82 & 0.83 & 0.73 & 0.76 & 0.98 & 0.98 & 0.97 \\
\hline Min. Split-Half Reliability & 0.54 & 0.64 & 0.64 & 0.70 & 0.67 & 0.35 & 0.71 & 0.70 & 0.80 & 0.63 & 0.67 & 0.89 & 0.85 & 0.86 \\
\hline Alpha & 0.72 & 0.74 & 0.88 & 0.80 & 0.73 & 0.43 & 0.81 & 0.78 & 0.81 & 0.69 & 0.73 & 0.95 & 0.94 & 0.94 \\
\hline
\end{tabular}

Note. Bold indicates $p<.01$. Italicised indicates $p<.05$. A version of this table with $95 \%$ confidence intervals can be found in the

Supplementary Materials (available at osf.io/cwbgv). 
Table 3

Random Effects Covariance Matrix

\begin{tabular}{lcccccc}
\hline Statement Type & \multicolumn{2}{c}{ PPBS } & \multicolumn{2}{c}{ Profound } & Mundane \\
\hline PPBS & $\mathbf{0 . 2 5}$ & {$[.19, .33]$} & & & & \\
Profound & $\mathbf{0 . 0 7}$ & {$[.03, .10]$} & $\mathbf{0 . 1 0}$ & {$[. \mathbf{0 7}, \mathbf{. 1 4}]$} & & \\
Mundane & $\mathbf{0 . 1 7}$ & {$[.07, .27]$} & 0.03 & {$[-.04, .09]$} & $\mathbf{1 . 0 7}$ & {$[. \mathbf{8 4}, \mathbf{1 . 3 6}]$} \\
\hline
\end{tabular}

Note. Bold indicates $p<.001 .95 \%$ Confidence Intervals in brackets.

Table 4

Descriptive Statistics for Signal Detection Parameters and Correlations with Personality

\begin{tabular}{|c|c|c|c|c|c|c|c|c|}
\hline & \multicolumn{2}{|c|}{ Discrimination } & \multicolumn{2}{|c|}{ Response Bias } & \multicolumn{2}{|r|}{ Hits } & \multicolumn{2}{|c|}{ False Alarms } \\
\hline Criterion & -.25 & {$[.08, .40]$} & & & & & & \\
\hline False Alarms & & & & & 0.28 & [ & & \\
\hline \multicolumn{9}{|c|}{ Intelligence and Intellect Measures } \\
\hline Cognitive Ability & .14 & {$[-.02, .30]$} & -.09 & {$[-.08, .25]$} & .04 & {$[-.13, .20]$} & -.13 & {$[-.29, .04]$} \\
\hline Cognitive Reflection & .19 & {$[.01, .34]$} & .01 & {$[-.18, .15]$} & .18 & {$[.01, .33]$} & -.10 & {$[-.25, .08]$} \\
\hline Need for Cognition & .13 & {$[-.04, .29]$} & -.02 & {$[-.15, .18]$} & .07 & {$[-.10, .23]$} & -.09 & {$[-.25, .07]$} \\
\hline BFAS Intellect & .17 & {$[-.00, .32]$} & -.03 & {$[-.14, .20]$} & .11 & {$[-.06, .27]$} & -.14 & {$[-.30, .03]$} \\
\hline IPIP Intellect & .26 & {$[.09, .40]$} & -.10 & {$[-.07, .26]$} & .08 & {$[-.09, .24]$} & -.22 & {$[-.37,-.06]$} \\
\hline Liberalism & .12 & {$[-.04, .28]$} & -.05 & {$[-.12, .21]$} & .07 & {$[-.09, .24]$} & -.11 & {$[-.27, .06]$} \\
\hline \multicolumn{9}{|l|}{ Openness Measures } \\
\hline Openness & .13 & {$[-.03, .29]$} & .00 & {$[-.17, .17]$} & .10 & {$[-.07, .26]$} & -.08 & {$[-.24, .09]$} \\
\hline Imagination & .07 & {$[-.09, .24]$} & .07 & {$[-.23, .10]$} & .13 & {$[-.04, .29]$} & .00 & {$[-.16, .17]$} \\
\hline Artistic Interests & .14 & {$[-.03, .30]$} & .05 & {$[-.21, .12]$} & .14 & {$[-.03, .29]$} & -.04 & {$[-.20, .13]$} \\
\hline Emotionality & .09 & {$[-.07, .26]$} & .08 & {$[-.24, .08]$} & .13 & {$[-.04, .29]$} & .02 & {$[-.15, .19]$} \\
\hline Adventurousness & .02 & {$[-.14, .19]$} & -.25 & {$[.09, .40]$} & -.25 & {$[-.40,-.08]$} & -.19 & {$[-. .35,-.03]$} \\
\hline \multicolumn{9}{|l|}{ Apophenia Measures } \\
\hline Ontological Confusions & -.27 & {$[-.42,-.11]$} & .15 & {$[-.31, .02]$} & -.06 & {$[-.22, .11]$} & .26 & {$[.10, .41]$} \\
\hline Paranormal Beliefs & -.23 & {$[-.38,-.06]$} & .14 & {$[-.30, .03]$} & -.04 & {$[-.21, .12]$} & .22 & {$[.06, .37]$} \\
\hline $\begin{array}{l}\text { Unusual Beliefs \& } \\
\text { Experiences }\end{array}$ & -.13 & {$[-.29, .03]$} & .06 & {$[-.23, .10]$} & -.03 & {$[-.20, .14]$} & .12 & {$[-.05, .28]$} \\
\hline Mean & & 0.73 & & 0.65 & & 10.03 & & 7.26 \\
\hline SD & & 0.82 & & 0.57 & & 2.02 & & 3.19 \\
\hline Skewness & & 0.45 & & -0.65 & & -1.72 & & -0.58 \\
\hline Kurtosis & & 0.04 & & 1.74 & & 4.72 & & -0.49 \\
\hline
\end{tabular}

Note. Bold indicates $p<.05 .95 \%$ Confidence Intervals in brackets. 
Table 5

Descriptive Statistics and Reliability Estimates of Each Statement Type, and Correlations Among Statement Types and Between Statement Types and Personality

\section{PPBS}

Profound

Statement Types

Profound

$.24[.08, .38]$

Intelligence and Intellect Measures

Cognitive Ability

$-.16[-.31, .00] \quad .01 \quad[-.15, .16]$

Cognitive Reflection

$\mathbf{- . 1 9}[-.33,-.03] \quad .09 \quad[-.07, .25]$

Intellect

$.02[-.14, .17] \quad .10 \quad[-.06, .25]$

Intellectual Curiosity

$.00 \quad[-.16, .16] \quad .10 \quad[-.06, .25]$

Openness Measures

Openness

$-.09 \quad[-.25, .06] \quad .11 \quad[-.05, .26]$

Creative Imagination

$.00 \quad[-.16, .16] \quad .07 \quad[-.09, .22]$

Aesthetic Sensitivity

$-.19[-.33,-.03] \quad .10 \quad[-.06, .25]$

Apophenia Measures

Core-Knowledge

Confusions

$.14 \quad[-.02, .29] \quad-.06 \quad[-.21, .10]$

Paranormal Beliefs

$.18[.02, .33] \quad .15 \quad[.00, .30]$

Magical Ideation

$.07 \quad[-.09, .22] \quad .06 \quad[-.09, .22]$

Mean

2.68

3.11

SD

0.41

0.32

Skewness

$-0.69$

$-0.41$

Kurtosis

1.48

0.86

Max. Split-Half Reliability

.90

.81

Min. Split-Half Reliability

.63

.41

Alpha

.89

.79

Note. Bold indicates $p<.05 .95 \%$ Confidence Intervals in brackets. 
Table 6

Correlations, Descriptive Statistics, and Reliability Estimates of the Personality Scales

\begin{tabular}{|c|c|c|c|c|c|c|c|c|c|c|c|}
\hline & & 1 & 2 & 3 & 4 & 5 & 6 & 7 & 8 & 9 & 10 \\
\hline & \multicolumn{11}{|c|}{ Intelligence and Intellect Measures } \\
\hline 1 & Cognitive Ability & & & & & & & & & & \\
\hline 2 & Cognitive Reflection & .55 & & & & & & & & & \\
\hline 3 & Intellect & .15 & .11 & & & & & & & & \\
\hline \multirow[t]{2}{*}{4} & Intellectual Curiosity & .19 & .12 & .58 & & & & & & & \\
\hline & Openness Measures & & & & & & & & & & \\
\hline 5 & Openness & .14 & .16 & .39 & .42 & & & & & & \\
\hline 6 & Creative Imagination & .20 & .06 & .48 & .50 & .26 & & & & & \\
\hline \multirow[t]{2}{*}{7} & Aesthetic Sensitivity & .12 & -.02 & .28 & .41 & .64 & .40 & & & & \\
\hline & Apophenia Measures & & & & & & & & & & \\
\hline 8 & Core-Knowledge Confusions & -.31 & -.16 & -.03 & -.07 & -.04 & -.07 & -.05 & & & \\
\hline 9 & Paranormal Beliefs & -.08 & -.12 & -.08 & -.03 & -.04 & -.10 & .05 & .18 & & \\
\hline \multirow[t]{8}{*}{10} & Magical Ideation & .02 & -.01 & -.09 & .08 & -.03 & -.13 & .03 & .08 & .55 & \\
\hline & Mean & 6.55 & 1.45 & 4.65 & 5.24 & 4.87 & 5.17 & 5.01 & 2.55 & 3.15 & 3.06 \\
\hline & $\mathrm{SD}$ & 3.05 & 1.62 & 0.83 & 0.91 & 0.73 & 0.87 & 1.16 & 0.58 & 1.03 & 0.99 \\
\hline & Skewness & 0.25 & 1.17 & 0.03 & -0.12 & 0.40 & -0.37 & -0.26 & 0.16 & -0.04 & 0.13 \\
\hline & Kurtosis & -0.33 & 0.80 & -0.26 & -0.28 & 0.13 & -0.18 & -0.87 & -0.04 & -0.73 & -0.39 \\
\hline & Max. Split-Half Reliability & .81 & .78 & .86 & .63 & .78 & .69 & .77 & .93 & .96 & .90 \\
\hline & Min. Split-Half Reliability & .48 & .56 & .69 & .54 & .30 & .45 & .68 & .72 & .77 & .72 \\
\hline & Alpha & .70 & .67 & .79 & .59 & .63 & .61 & .72 & .87 & .91 & .83 \\
\hline
\end{tabular}


Note. Bold indicates $p<.01$. Italicised indicates $p<.05$. This table with $95 \%$ confidence intervals can be found in the Supplementary Materials (available at osf.io/cwbgv). 
Table 7

Random Effects Covariance Matrix

\begin{tabular}{lcccc}
\hline & \multicolumn{2}{c}{ PPBS } & \multicolumn{2}{c}{ Profound } \\
\hline PPBS & $\mathbf{0 . 1 5}$ & {$[.12, .20]$} & & \\
Profound & $\mathbf{0 . 0 4}$ & {$[.01, .06]$} & $\mathbf{0 . 0 8}$ & {$[.06, .11]$} \\
\hline
\end{tabular}

Note. Bold indicates $p<.01 .95 \%$ Confidence

Intervals in brackets.

Table 8

Descriptive Statistics for Signal Detection Parameters and Correlations with Personality

\begin{tabular}{|c|c|c|c|c|c|c|c|c|}
\hline & \multicolumn{2}{|c|}{ d-Prime } & \multicolumn{2}{|c|}{ Criterion } & \multicolumn{2}{|r|}{ Hits } & \multicolumn{2}{|c|}{ False Alarms } \\
\hline Criterion & -.29 & {$[-.43,-.14]$} & & & & & & \\
\hline False Alarms & & & & & .19 & {$[.03, .34]$} & & \\
\hline \multicolumn{9}{|c|}{ Intelligence and Intellect Measures } \\
\hline Cognitive Ability & .21 & {$[.05, .35]$} & -.15 & {$[-.30, .00]$} & -.01 & {$[-.17, .15]$} & -.22 & {$[-. .37,-.07]$} \\
\hline Cognitive Reflection & .27 & {$[.11, .41]$} & -.05 & {$[-.21, .10]$} & .13 & {$[-.03, .28]$} & -.19 & {$[-. .34,-.03]$} \\
\hline Intellect & .11 & {$[-.05, .26]$} & .01 & {$[-.15, .16]$} & .07 & {$[-.09, .22]$} & -.03 & {$[-.19, .12]$} \\
\hline Intellectual Curiosity & .13 & {$[-.03, .28]$} & .04 & {$[-.12, .20]$} & .11 & {$[-.05, .26]$} & -.03 & {$[-.19, .12]$} \\
\hline \multicolumn{9}{|l|}{ Openness Measures } \\
\hline Openness & .16 & {$[.00, .31]$} & -.03 & {$[-.18, .13]$} & .09 & {$[-.07, .24]$} & -.12 & {$[-.27, .04]$} \\
\hline Creative Imagination & -.03 & {$[-.18, .13]$} & -.05 & {$[-.21, .10]$} & -.03 & {$[-.19, .12]$} & -.02 & {$[-.17, .14]$} \\
\hline Aesthetic Sensitivity & .20 & {$[.04, .34]$} & -.06 & {$[-.22, .09]$} & .07 & {$[-.09, .23]$} & -.19 & {$[-. .33,-.03]$} \\
\hline \multicolumn{9}{|l|}{ Apophenia Measures } \\
\hline $\begin{array}{l}\text { Core-Knowledge } \\
\text { Confusions }\end{array}$ & -.19 & {$[-.33,-.03]$} & .07 & {$[-.09, .22]$} & -.07 & {$[-.23, .08]$} & .17 & {$[.02, .32]$} \\
\hline Paranormal Beliefs & -.05 & {$[-.21, .11]$} & .21 & {$[.06, .36]$} & .19 & {$[.04, .34]$} & .16 & {$[.00, .30]$} \\
\hline Magical Ideation & .02 & {$[-.14, .17]$} & .10 & {$[-.06, .25]$} & .12 & {$[-.03, .28]$} & .04 & {$[-.12, .19]$} \\
\hline Mean & & 0.44 & & 0.55 & & 23.08 & & 18.49 \\
\hline $\mathrm{SD}$ & & 0.67 & & 0.42 & & 3.98 & & 6.10 \\
\hline Skewness & & 0.20 & & -0.13 & & -0.95 & & -0.39 \\
\hline Kurtosis & & 0.38 & & 1.79 & & 1.67 & & -0.24 \\
\hline
\end{tabular}

Note. Bold indicates $p<.05 .95 \%$ Confidence Intervals in brackets. 


\begin{tabular}{|lc}
\hline Data & Simplex Value \\
Construct & 2.01 \\
Intelligence & 1.41 \\
Competence & 1.08 \\
Need for Cognition & 1.03 \\
Quickness & 0.79 \\
Intellectual Curiosity & 0.72 \\
Ingenuity & 0.68 \\
Values & 0.64 \\
Intellect & 0.44 \\
Ideas & 0.37 \\
Introspection & 0.04 \\
Actions & -0.02 \\
Imagination & -0.04 \\
Depth & -0.08 \\
Fantasy & -0.21 \\
Aesthetics & -0.4 \\
Reflection & -0.54 \\
\hline Feelings & -0.76 \\
MPQ Absorption (PIAS) & -1.05 \\
MPQ Absorption (Sentience) & -1.24 \\
\hline Fantasy Proneness & -1.59 \\
Paranormal Beliefs & -1.72 \\
\hline Magical Ideation & -1.75 \\
\hline CES Absorption & \\
\hline
\end{tabular}

Figure Caption

The O/I simplex (adapted from DeYoung et al., 2012) shows the order of constructs as Intelligence, Intellect, Openness, and Apophenia.

Figure

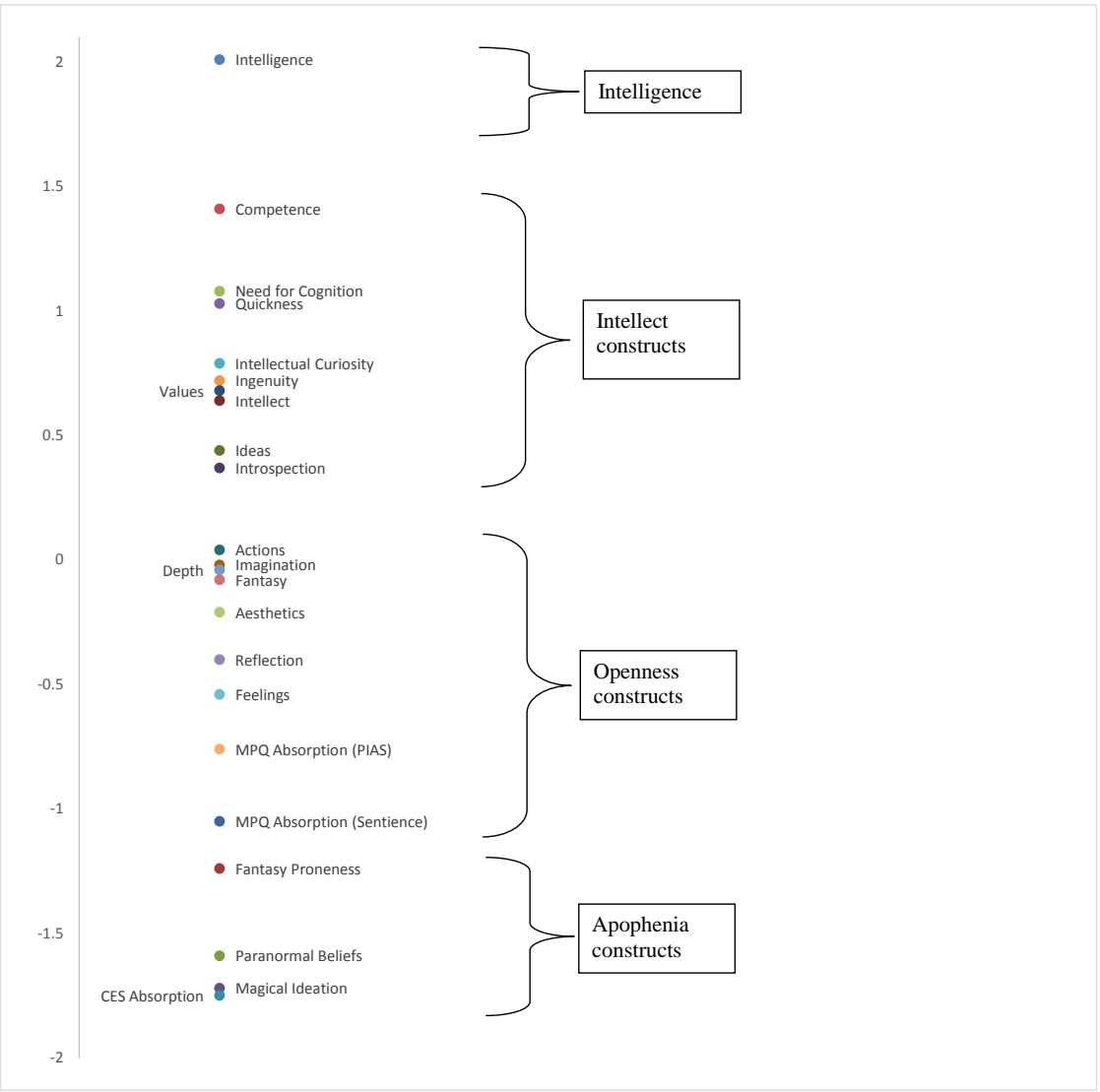

This article is protected by copyright. All rights reserved. 
Data

Statement Type Mean Lower Bound Upper Bound UB-Mean

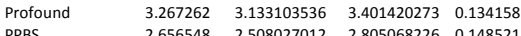

$\begin{array}{llllll}\text { PPBS } & 2.656548 & 2.508027012 & 2.805068226 & 0.148521\end{array}$
Figure Caption

Mean statement type ratings for each statement type. Error bars represent $95 \%$ confidence intervals. Ratings were on a Likert scale from 1 to 4 .

Figure

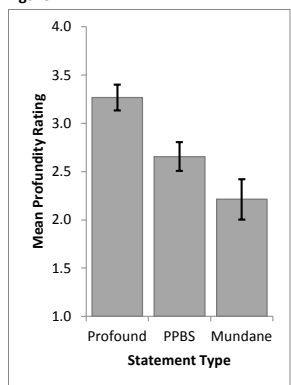

This article is protected by copyright. All rights reserved. 
Data

Construct

PPBS

Imagination

Artistic Interests

Emotionality

Adventurousness

Liberalism

IPIP Intellect

BFAS Intellec

Openness

Need for Cognition

Onotological Confusions

Paranormal Belief

Unusual Beliefs \& Experiences

Cognitive Ability

Cognitive Reflection
Simplex Value

1.204787

0.162251

$-0.06052$

0.147553

$-0.22773$

$-0.40999$

$-0.51562$

$-0.5512$

$-0.09735$

$-0.63126$

0.938212

1.000793

0.796365

$-0.951$

$-0.80529$
Figure Caption

The O/I simplex solution for Study 1 .

Figure

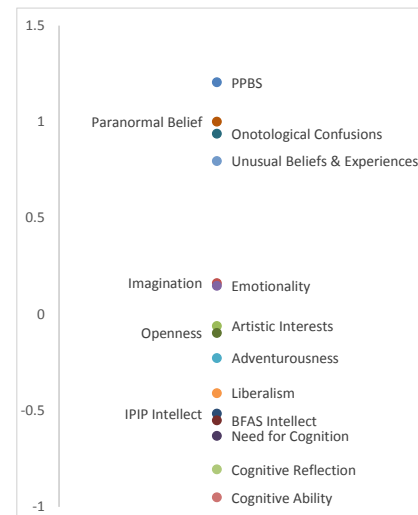

This article is protected by copyright. All rights reserved. 
Data

Construct

Cognitive Ability

Cognitive Reflection

PPBS

Core-Knowledge Confusions

Openness

Intellect

Aesthetic Sensitivity

Creative Imagination

Intellectual Curiosity

Paranormal Belief

Magical Ideation
Figure Caption

The O/I simplex solution for Study 2 .

Figure

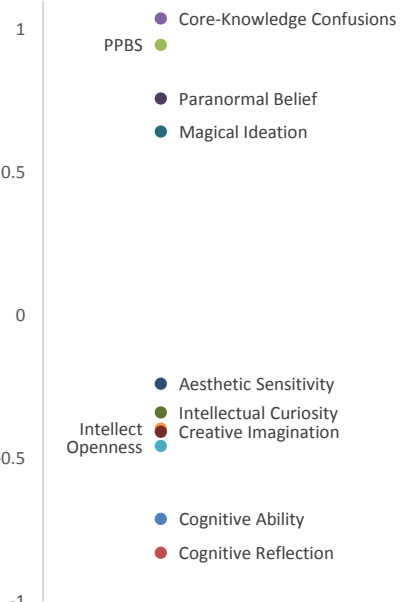




\section{University Library}

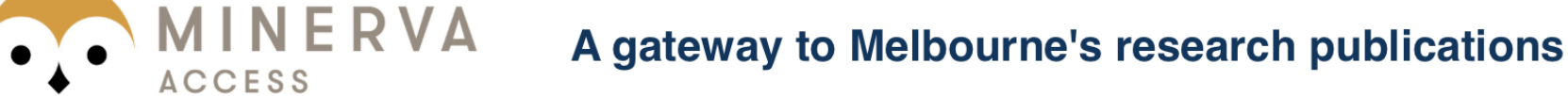

Minerva Access is the Institutional Repository of The University of Melbourne

Author/s:

Bainbridge, TF;Quinlan, JA;Mar, RA;Smillie, LD

Title:

Openness/Intellect and Susceptibility to Pseudo-Profound Bullshit: A Replication and Extension

Date:

2019-01-01

Citation:

Bainbridge, T. F., Quinlan, J. A., Mar, R. A. \& Smillie, L. D. (2019). Openness/Intellect and Susceptibility to Pseudo-Profound Bullshit: A Replication and Extension. EUROPEAN JOURNAL OF PERSONALITY, 33 (1), pp.72-88. https://doi.org/10.1002/per.2176.

Persistent Link:

http://hdl.handle.net/11343/285218 